\title{
Cerebral Venous Sinus Thrombosis- An Update
}

\author{
RAI IB NAYAN CHOWDHURY ${ }^{1}$, KAZ MOHIBUR RAHMAN ${ }^{1}$, SHARIF UDDIN KHAN ${ }^{1}$, MD AHSAN HABIB², TITU MIAH ${ }^{3}$, \\ KFM AYAZ3 ${ }^{3}$, SUDI P RANJ AN DEB ${ }^{4}$, NAZRUL ISLAM ${ }^{5}$, SAMSUL AREFI N PATWARY6
}

\section{Introduction:}

Cerebral venous sinus thrombosis (CVST) is a rare form of stroke that results from thrombosis (a blood clot) of the dural venous sinuses, which drain blood from the brain. Cerebral venous sinus thrombosis is not common. In adult estimated annual incidence is 3-4 cases per million. It is most common in the third decade. Among all patients $75 \%$ are female. It has been suggested that the use of oral contraceptives in women is behind the higher incidence in female. ${ }^{1}$ CVST is more common in the Middle East due to high prevalence of Behçet's disease in these area. ${ }^{1-3} \mathrm{~A}$ Canadian study reported that In children CVST occurs in 6.7 per million annually, $43 \%$ occur in the newborn (less than one month old), and a further $10 \%$ in the first year of life. ${ }^{4}$

\section{Pathogenesis:}

The superficial and the deep vein, empty into the dural venous sinuses, which carry blood to the jugular vein and then to the heart. In cerebral venous sinus thrombosis, blood clots usually form both in the veins of the brain and the venous sinuses. The thrombosis of the veins themselves causes venous infarction. This results in both vasogenic and cytotoxic cerebral edema, and leads to small petechial haemorrhage that may coalesce into large haematomas. Thrombosis of the sinuses is the main mechanism behind the increase in intracranial pressure due to decreased resorption of cerebrospinal fluid (CSF). ${ }^{1,5}$

The three major mechanisms for the formation of a blood clot are enumerated in Virchow's triad: alterations in normal blood flow, injury to the blood vessel wall, and alterations in the constitution of blood (hypercoagulability). Blood clot forms due to an imbalance between coagulation (the formation of the insoluble blood protein fibrin) and fibrinolysis. Most cases of cerebral venous sinus thrombosis are due to hypercoagulability. ${ }^{1,6,7}$

\section{Symptoms:}

Headache; Nine in ten people with sinus thrombosis have a headache; this tends to worsen over the period of several days, but may also develop suddenly (thunderclap headache). ${ }^{1}$

Abnormal vision: The intracranial pressure (pressure around the brain) may rise, causing papilloedema (swelling of the optic disc) which may be experienced as visual obscurations. In severely raised intracranial pressure, the level of consciousness is decreased, the blood pressure rises, the heart rate falls and the patient may assume an abnormal posture. ${ }^{1,7}$

Stroke : such as weakness of the face and limbs on one side of the body, This does not necessarily affect one side of the body as in the more common "arterial" stroke. 1,6

Seizures : These are mostly seizures affecting only one part of the body and unilateral (occurring on one side), but occasionally the seizures are generalized and rarely they lead to status epilepticus. ${ }^{1}$

Other common symptoms in the elderly with this condition are otherwise unexplained changes in mental status and a depressed level of consciousness. $5,6,8$

Causes: Cerebral venous sinus thrombosis is more common in particular situations. $85 \%$ of patients have at least one of these risk factors. ${ }^{1,8-10}$

\section{- Congenital:}

Thrombophilia, a tendency to develop blood clots due to abnormalities in coagulation, e.g. factor $\mathrm{V}$ Leiden, deficiency of protein C, protein $\mathrm{S}$ or antithrombin, or related problems.

\section{- Acquired}

1. Nephrotic syndrome, a kidney problem causing protein loss in the urine.

1. Assistant Professor of Neurology, DMCH

2. Registrar, Dept. of Neurology, DMCH

3. Assistant Professor of Medicine, DMCH

4. Resident Physician, Medicine, DMCH

5. Registrar, Medicine Unit 8, DMCH

6. Assistant Registrar, Medicine Unit 1, DMCH

Correspondence: Dr Rajib Nayan Chowdhury, Assistant Professor of Neurology, Dhaka Medical College Hospital. Email: rajibchow86@yahoo.com. Mobile; 01715176567 
2. Chronic inflammatory diseases, such as inflammatory bowel disease, lupus and Behçet's disease.

3. Pregnancy and puerperium (the period after giving birth).

4. Polycythemia vera and paroxysmal nocturnal hemoglobinuria

5. Use of estrogen-containing forms of hormonal contraception

6. Meningitis and infections of the ear, nose and throat area such as mastoiditis and sinusitis

7. Direct injury to the venous sinuses

8. Medical procedures in the head and neck area

Table-I

Causes of Cerebral Venous Sinus Thrombosis ${ }^{9}$

Predisposing Systemic causes

Dehydration

Pregnancy

Behcet's disease

Thrombophilia

Hypotension

Oral contraceptive

Local Causes

Paranasal Sinusitis

Meningitis, subdural empyema

Penetrating head and eye wound

Facial skin infection

Otitis media, mastoiditis

Skull fracture

\section{Investigations}

Neuroimaging

- Computed tomography (CT) and Magnetic resonance imaging (MRI):

Both uses various types of radiocontrast to perform a venogram and visualise the veins around the brain. ${ }^{11,12}$

\section{- Computed tomography with radio contrast}

Uses radio contrast in the venous phase (CT venography or CTV), has a detection rate that in some regards exceeds that of MRI. The test involves injection into a vein (usually in the arm) of a radio opaque substance, and time is allowed for the bloodstream to carry it to the cerebral veins - at which point the scan is performed. It has a sensitivity of $75-100 \%$ and a specificity of $81-100 \%$. In the first two weeks, the "empty delta sign" may be observed (in later stages, this sign may disappear).6, 12,13

\section{- Magnetic resonance venography}

Employs the same principles, but uses MRI as a scanning modality. MRI has the advantage of being better at detecting damage to the brain itself as a result of the increased pressure on the obstructed veins. ${ }^{6,12,13}$

\section{- Cerebral angiography}

May demonstrate smaller clots than CT or MRI. This, however, requires puncture of the femoral artery with a sheath and advancing a thin tube through the blood vessels to the brain where radio contrast is injected before $\mathrm{X}$-ray images are obtained. It is therefore only performed if all other tests give unclear results or when other treatments may be administered during the same procedure. ${ }^{6,12,13}$

\section{- Other investigations: D-dimer}

D-dimer blood test, already in use for the diagnosis of other forms of thrombosis, with cerebral sinus thrombosis, has a sensitivity of $97.1 \%$, a negative predictive value of $99.6 \%$, a specificity of $91.2 \%$, and a positive predictive value of $55.7 \%$. Furthermore, the level of the D-dimer correlated with the extent of the thrombosis. ${ }^{14}$

In most patients, the direct cause for the cerebral sinus thrombosis is not readily apparent. Identifying a source of infection is crucial; it is common practice to screen for various forms of thrombophilia (a propensity to form blood clots protein c, protein s measurement). ${ }^{1}$

\section{Treatment}

\section{Anticoagulation}

Heparin or low molecular weight heparin is the initial treatment, followed by Warfarin, provided there are no other bleeding risks that would make these treatments unsuitable. ${ }^{3,15,16}$

In case of extensive hemorrhage anticoagulation is not recommended, in that case, recommendation is to repeat the imaging after 7-10 days. If the hemorrhage has decreased in size, anticoagulants are commenced, while no anticoagulants are given if there is no reduction. ${ }^{10}$

The duration of Warfarin treatment depends on the circumstances and underlying causes of the condition.

a) If the thrombosis developed under temporary circumstances (e.g. pregnancy); Warfarin is given for 3 months.

b) If the condition was unprovoked but there are no clear causes or a "mild" form of thrombophilia; Warfarin is given for 6 to 12 months.

c) If there is a severe underlying thrombosis disorder, Warfarin treatment may need to continue indefinitely. ${ }^{3}$

Thrombolysis: (removal of the blood clot with medication)

a) Either systemically by injection into a vein or

b) Directly into the clot during angiography.

The 2006 European Federation of Neurological Societies guideline recommends that thrombolysis is only used in patients who deteriorate despite adequate treatment, and other causes of deterioration have been eliminated. Bleeding into the brain and in other sites of the body is a major concern in the use of thrombolysis. ${ }^{3,14,15}$ 


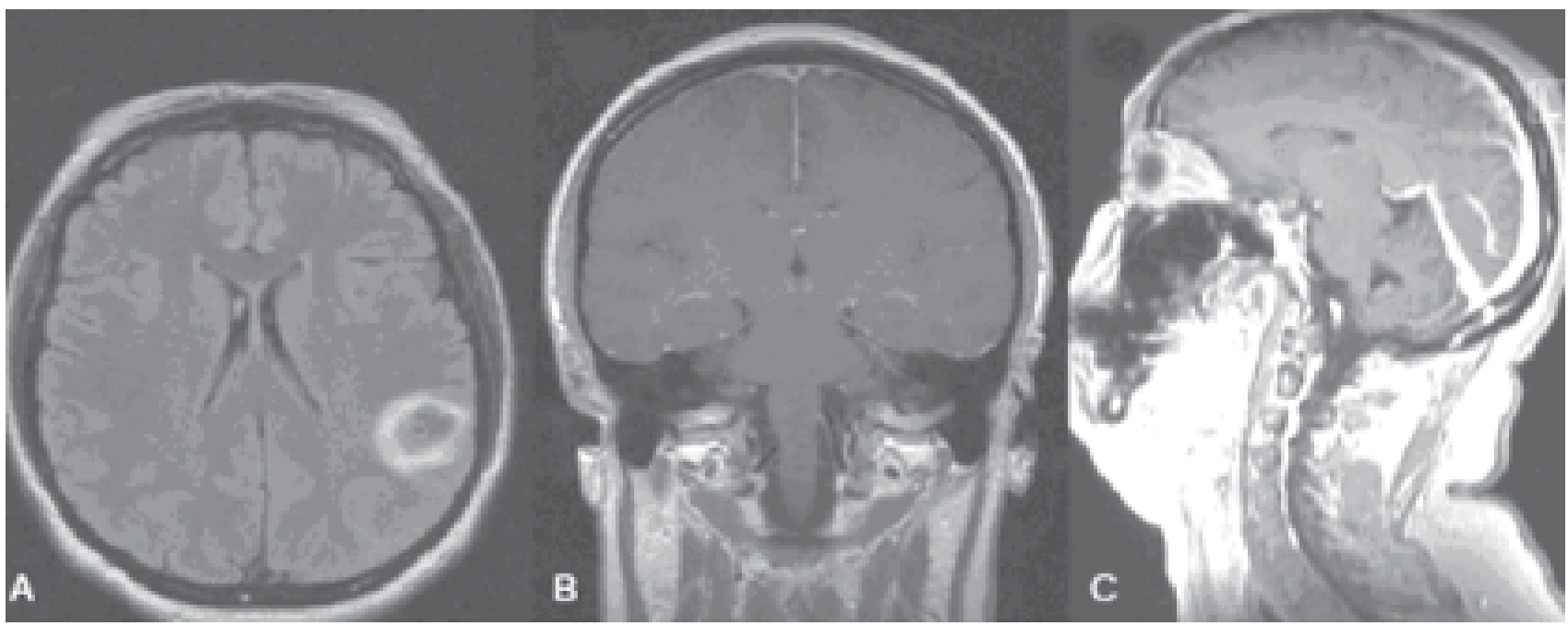

Figure-1: Fig.-A; MRI of brain, FLAIR image; of a young women presented with sudden onset of focal seizure, showed a resolving hematoma in left parietal region. Fig.-B; MRI with contrast (Coronal ); showing empty delta sign . (Contrast is not taken by clot) $\quad$ Fig.-C; MRV showing poor visualization of anterior part of superior sagittal sinus

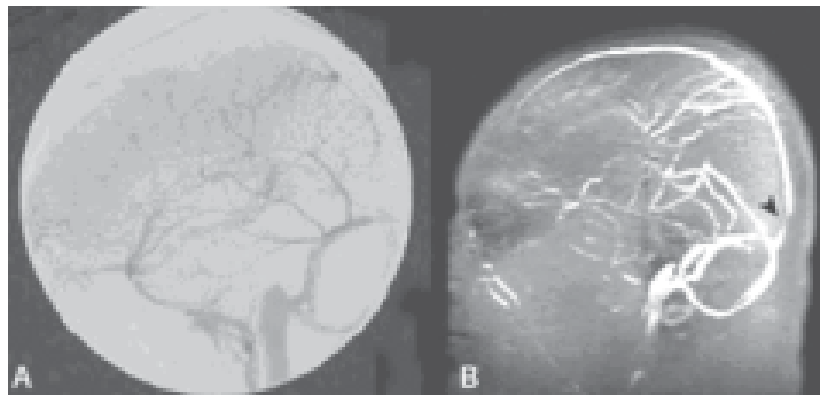

Figure 2: A) Cerebral angiogram (lateral view) showing non visualization of Superior sagittal sinus B) After treatment with Heparin \& Warfarin MRV showing recanalization of sinuses with persistant filling defect in straight sinus (arrow).

\section{Prognosis}

Bad prognostic factors are

1. Aged over 37 years

2. Male,

3. Affected by coma,

4. Mental status disorder,

5. Intracerebral hemorrhage,

6. Thrombosis of the deep cerebral venous system,

7. Central nervous system infection

8. Cancer.

These were the findings of large scale study on the natural history and long-term prognosis of CVST with 16 months follow-up, $57.1 \%$ of patients had full recovery, 29.5\%/2.9\%/
$2.2 \%$ had respectively minor/moderate/severe symptoms or impairments, and $8.3 \%$ had died. The rate of recurrence was low $(2.8 \%)^{18,19}$

\section{Conclusion:}

Wide variability of presentation has made the clinical diagnosis of CVST a challenging one. Increased awareness and availability of better non invasive diagnostic techniques in recent days helped in diagnosing the condition. Simple antithrombotic treatment strategies provide a favorable long term outcome, keeping the more aggressive and potentially dangerous intervention procedures reserved for the high risk group. The disease being first detailed in 1825 by Ribes, the clinical recognition still remains a challenge for physicians.

\section{Conflict of Interest: None}

\section{References:}

1. Stam J. Thrombosis of the cerebral veins and sinuses". N. Engl. J. Med. 2005; 352 (17): 1791-8

2. Einhäupl K, Bousser MG, de Bruijn SF, et al.. EFNS guideline on the treatment of cerebral venous and sinus thrombosis. Eur. J. Neurol. 2006; 13 (6): 553-9

3. Daif A, Awada A, al-Rajeh S, et al. Cerebral venous thrombosis in adults. A study of 40 cases from Saudi Arabia. Stroke 1995; 26 (7): 1193-5

4. DeVeber G, Andrew M, Adams C, et al. Cerebral sinovenous thrombosis in children. N. Engl. J. Med. 2001; 345 (6): 41723

5. Ferro JM, Canhão P, Bousser MG, Stam J, Barinagarrementeria F. Cerebral vein and dural sinus thrombosis in elderly patients. Stroke 2005; 36 (9): 192732 
6. Dentali F, Gianni M, Crowther MA, Ageno W. Natural history of cerebral vein thrombosis: a systematic review. Blood 2006;108 (4): 1129-34

7. Ray BS, Dunbar HS. Thrombosis of the dural venous sinuses as a cause of pseudotumor cerebri. Ann. Surg. 1951; 134 (3): 376-86

8. National Institute for Health and Clinical Excellence. Clinical guideline 68: Stroke. London, 2008

9. Colledge NR, Walker BR, Ralston SH “Davidson’s Principles \& Practice of Medicine” 21 $1^{\text {st }}$ edition, Pp. 1191

10. Bousser MG, Chiras J, Bories J, Castaigne P. Cerebral venous thrombosis - a review of 38 cases. Stroke 1985; 16 (2): 199-213

11. Towbin A. The syndrome of latent cerebral venous thrombosis: its frequency and relation to age and congestive heart failure. Stroke 1973; 4 (3): 419-30.

12. Smith R, Hourihan MD. Investigating suspected cerebral venous thrombosis. BMJ 2007; 334 (7597): 794-5

13. Ray BS, Dunbar HS, Dotter CT. Dural sinus venography as an aid to diagnosis in intracranial disease. J. Neurosurg. 1951; 8 (1): 23-37
14. Ray BS, Dunbar HS, Dotter CT. Dural sinus venography as an aid to diagnosis in intracranial disease. J. Neurosurg. 1951; 8 (1): 23-37

15. Crassard I, Soria C, Tzourio C, et al. A negative D-dimer assay does not rule out cerebral venous thrombosis: a series of seventy-three patients._Stroke 2005; 36 (8): 1716-19

16. Stansfield FR. Puerperal cerebral thrombophlebitis treated by heparin. Br Med J 1942; (4239): 436-438

17. Martinelli I, Franchini M, Mannucci PM. How I treat rare venous thromboses”. Blood 2008; 112 (13): 4818-23

18. Sacco RL, Adams R, Albers G, et al. Guidelines for prevention of stroke in patients with ischemic stroke or transient ischemic attack: a statement for healthcare professionals from the American Heart Association/American Stroke Association Council on Stroke: co-sponsored by the Council on Cardiovascular Radiology and Intervention: the American Academy of Neurology affirms the value of this guideline. Circulation 2006; 113 (10): e409-49

19. Ferro JM, Canhão P, Stam J, Bousser MG, Barinagarrementeria F. Prognosis of cerebral vein and dural sinus thrombosis: results of the International Study on Cerebral Vein and Dural Sinus Thrombosis (ISCVT). Stroke 2004; 35 (3): 664-70 